\title{
Positive and negative contrast effects obtained following shifts in delayed water reward
}

\author{
MITRI E. SHANAB and ROBERT E. SPENCER \\ California State University, Fresno, California 93740
}

\begin{abstract}
In a two-shift experiment, four independent groups of thirsty rats were delayed $20 \mathrm{sec}$ before receiving the following treatments: LLL, LSL, SSS, SLS, with each letter denoting the magnitude of water reward received in each of the three phases of the experiment. Both a significant positive contrast effect (PCE) and a negative contrast effect (NCE) were obtained following the first shift. Weaker contrast effects were found in the second shift. The present results support and extend the generality of previous findings of studies using shifts in magnitude of food reward with superimposed delay as a control for ceiling effects.
\end{abstract}

In recent years numerous studies have attempted to replicate and extend Crespi's (1942) early findings concerning incentive contrast. A positive contrast effect (PCE) is said to have occurred when subjects shifted from a small to a larger reward perform at a significantly higher level than control subjects receiving the large reward all the time. A negative contrast effect (NCE) occurs when subjects shifted from a large to a smaller reward perform at a significantly lower level than control subjects receiving the small reward all the time.

Crespi's (1942) findings of NCE in the runway based on shifts in food reward have been successfully replicated in many laboratories (Cox, 1975; Dunham, 1968). Attempts to replicate Crespi's findings of PCE failed repeatedly. Bower (1961) attributed this failure to possible ceiling effects inherent in the running response. In other words, subjects shifted to large reward do not exceed the level of their controls because they cannot run faster than some upper limit imposed by the large reward. When appropriate controls for the ceiling effects were introduced, PCE was consistently obtained (Mellgren, 1972; Shanab, Birnbaum, \& Cavallaro, 1974; Shanab, Sanders, \& Premack, 1969). In these studies the PCE was obtained when shifts in reward magnitude were introduced along with delay.

Despite the consistent finding of NCE when solid food is downshifted, no such effect was obtained when either magnitude or concentration of liquid sucrose reward was downshifted (Ison \& Rosen, 1968; Rosen, 1966). Even when both magnitude and concentration were downshifted simultaneously, no NCE was reported (Barnes \& Tombaugh, 1973; Flaherty, Riley, \& Spear, 1973). With the introduction of repeated shifts, however, significant results have been obtained. A repeated shift involves returning subjects to conditions previously experienced. Shanab, France, and Young (1976) found both a PCE and a NCE during the second

Reprint requests should be sent to Mitri E. Shanab, Department of Psychology, California State University, Fresno, California 93740. shift for subjects returned to both the large and small reward conditions, respectively. In this study, reward consisted of either 1.75 or $.20 \mathrm{cc}$ of $8 \%$ sucrose reinforcement. In a subsequent repeated-shifts study, subjects were shifted to either 2- or 20-sec delay of $18 \%$ sucrose reward (Shanab, Domino, \& Melrose, 1977). Although no PCE was found in either the first or second shift, a significant NCE was obtained in both shifts.

Very few studies have investigated shifts in water reward in the runway. Sgro and Weinstock (1963) shifted thirsty rats from either a 15 -sec or 7.5 -sec delay of reward to immediate reward. The reward consisted of 20-sec access to a drinking tube. A significant PCE was reported only for those subjects shifted from a delay of $15 \mathrm{sec}$ to immediate reward. Recently, Ferrell and Shanab (1975) investigated the effects of shifts in delay of water reward in a two-phase design. Thirsty rats were rewarded with 16 -sec water access after a delay of 0,8 , or $16 \mathrm{sec}$ in the preshift phase. In the shift phase, the subjects in each main group were subdivided into three groups and were either continued on the preshift delay or shifted to one of the other two delay intervals. Although neither a significant PCE nor NCE was obtained, a graphical PCE was observed in all sections of the runway. Apparently, there is only one study in the literature (viz., Sgro \& Weinstock, 1963) that reported a significant PCE based on shifts in delay of water reward. It should be noted that Sgro and Weinstock (1963) had to eliminate the 15 slowest rats from their analysis, thus limiting the generalizability of their results. Similarly, there is only one study (viz., Ferrell \& Shanab, 197.5) that studied NCE based on shifts in delay of reward and reported negative results.

The sparsity of studies investigating shifts in water reward is not limited to the delay variable but the magnitude variable as well, for there are no published studies that have investigated contrast effects as a function of shifts in magnitude of water reinforcement. The present study was primarily aimed at filling this gap. Since numerous attempts at our laboratory to 
obtain contrast effects following shifts in delay, magnitude, or schedule of water reward all failed, the present design incorporated three procedures aimed at maximizing the conditions for the emergence of contrast. First, a 20-sec delay was superimposed on the manipulated magnitude of reward that consisted of either 2- or 20-sec access to water. Although the delay interval is expected to enhance the emergence of PCE by eliminating the ceiling effect, it may also depress responding to such an extent that a NCE would be precluded. However, it was hoped that by using a repeated-shifts procedure, the floor effect might be overcome, since repeated shifts have been shown to enhance both contrast effects. Thus, the repeated shifts constituted the second kind of procedure used to maximize the likelihood of obtaining contrast effects. Third, massed as opposed to the more common spaced training was used. Capaldi (1972) has shown that, at least for NCE, the effects of shifts in magnitude of reward are more pronounced when trials are massed rather than spaced.

Accordingly, it was predicted that a PCE would occur in Phase 2 for the upshifted group, although no NCE would probably be displayed by the downshifted group due to the floor effects of the delay conditions. It was also predicted that in Phase 3 both a PCE and a NCE would occur. The prediction of the latter effect is based on the assumption that the floor effects associated with the delay condition would be overcome by the effects of a repeated shift.

\section{METHOD}

\section{Design}

The experiment consisted of two phases. In Phase 1, 30 subjects were assigned to each of two reward conditions: access to water for either $2 \mathrm{sec}$ (S) or $20 \mathrm{sec}$ (L). In Phase 2, each main group was divided in half, resulting in four groups with 15 subjects/group, according to a 2 by 2 factorial design. One subgroup continued to receive the same reward as before, while the second was shifted to the other reward condition. In Phase 3, subjects were shifted back to their respective conditions of Phase 1. Thus the four groups run were: LLL, LSL, SSS, SLS. In all conditions, reward was delayed 20 sec.

\section{Subjects}

The subjects were 60 naive male albino rats of the SpragueDawley strain, about 90 days old at the beginning of the experiment.

\section{Apparatus}

A 1.5-m runway made of unpainted redwood was used. The runway was covered with Plexiglas and was $23 \mathrm{~cm}$ high and $10 \mathrm{~cm}$ wide throughout. The startbox was $18 \mathrm{~cm}$ long and $17 \mathrm{~cm}$ wide, while the goalbox was $30.5 \mathrm{~cm}$ long and $12 \mathrm{~cm}$ wide. The start- and goalboxes were each separated from the run section by guillotine doors. In the goalbox, a small metal plate $(2.5 \times 2.5 \mathrm{~cm})$ was fixed to the far wall and surrounded an aperture located $4.2 \mathrm{~cm}$ from the floor. Through this aperture, a drinking tube was presented to the subject automatically after the 20-sec delay interval and then was retracted after the prescribed access interval had elapsed. During the delay interval, the subject was confined to the goalbox by means of the second guillotine door, which separated that region from the run section. Four sets of photocells were installed in the runway. Interruption of any of the four photobeams started and/or stopped any one of the three Standard Electric timers that measured start, run, and goal times. The first through fourth photocells were located $6.4,21.5,103$, and $115 \mathrm{~cm}$ from the startbox, respectively.

\section{Procedure}

Upon arrival from the supplier, the subjects were housed in individual cages with free access to food and water and were handled daily for $2 \mathrm{~min}$ for 15 days. Subjects were then placed on a $23.75-\mathrm{h}$ water-deprivation schedule. At least $30 \mathrm{~min}$ after handling each day, subjects were given water access for $15 \mathrm{~min}$. After a total of 11 days on the deprivation schedule, subjects were given exploration in the runway. No water was provided in the runway during exploration. On the first day, each subject was given 90-sec exploration of the runway with the guillotine doors open and all equipment turned off. On the second and third days, the doors were operated in the same fashion as on regular trials, and the equipment was turned on to accustom the subjects to its sounds. Following this, 2 days of operant levels were taken by measuring the time taken by each subject to traverse the entire runway on the first run. On each of these days, subjects were given 20-sec access to water in the goalbox $30 \mathrm{~min}$ after the completion of their trial run in order to familiarize them with the water tube apparatus. Subjects were then randomly assigned to two main groups, and Phase 1 was started. This phase lasted 25 days. On the first 2 days of the phase, each subject received 1 trial/day, but thereafter each subject received 2 trials/day. On each trial, the subject was placed in the startbox and as soon as it oriented toward the run section both guillotine doors were opened. As soon as the rat entered the goalbox, the door was closed behind it. The 20-sec delay interval began when the subject broke the last photobeam located within the goalbox, after which the subject received access to the drinking tube for either 2 or 20 sec. If a subject failed to pass through a section of the runway in $60 \mathrm{sec}$, a time of $60 \mathrm{sec}$ was recorded for that and subsequent sections of the runway. Trials were massed with an intertrial interval of approximately $10 \mathrm{sec}$. Each subject received its 15 -min daily ration of water at least $30 \mathrm{~min}$ following its second daily trial, in both phases. In Phase 2, subjects were matched on the basis of their asymptotic performance levels in Phase 1, and a random half of each group was shifted to the opposite reward magnitude. Duration of access to the drinking tube was again either 2 or $20 \mathrm{sec}$, with a 20 -sec delay interval. Phase 2 was continued for 9 days at 2 trials/day. In Phase 3, which also lasted 9 days, subjects were returned to their respective conditions of Phase 1 . In all phases, the subjects had free access to food.

\section{RESULTS}

All analyses are based on mean running speed. An analysis of variance with repeated measures over the last four blocks of Phase 1 yielded nonsignificant results for both blocks and the interaction of blocks with treatments (both $F s<1$ ), indicating that the performance of the groups had stabilized by the end of Phase 1. The treatment effect was also not significant $[F(1,54)=3.02, p>.05]$, indicating that the groups did not differ at the end of acquisition training.

As Figure 1 shows, the upshifted group (SL) ran faster in Phase 2 than its control group (LL), displaying a PCE. A two-way analysis of variance test of total speed over all blocks with Phase 1 and Phase 2 conditions as the between factors yielded significant main effects $[\operatorname{Fs}(1,52)=13.93$ and 19.32 for the 


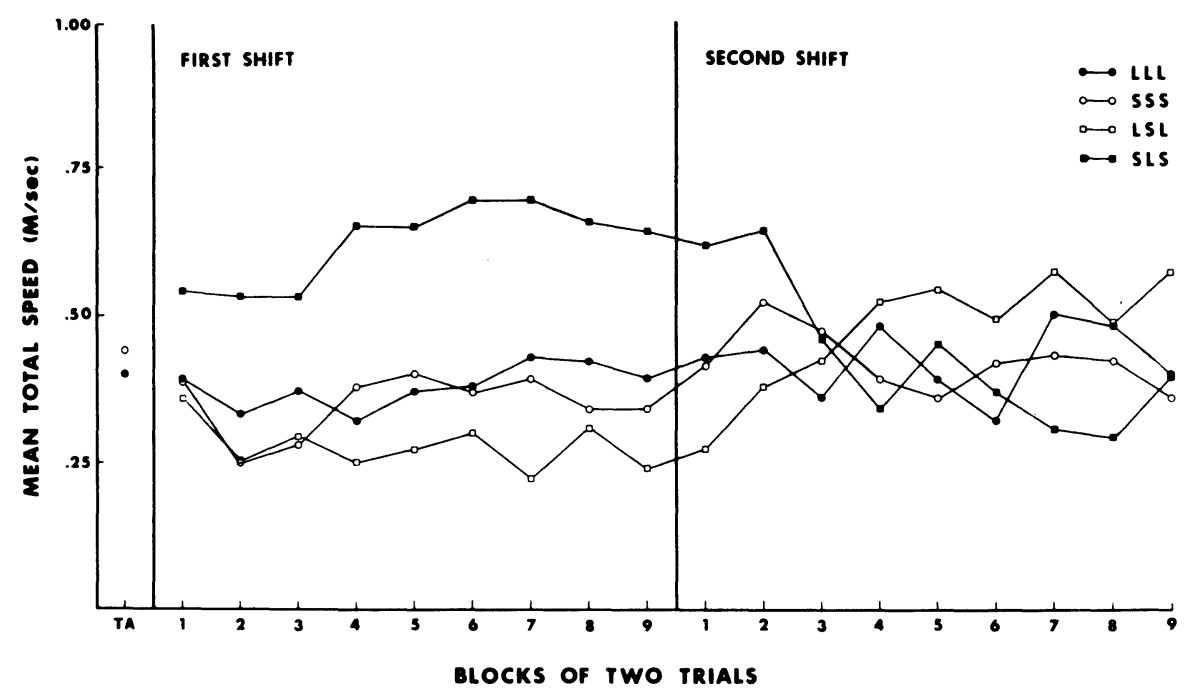

Figure 1. Mean total speed as a function of repeated shifts in magnitude of water reward.

respective factors, both $\mathrm{ps}<.01]$. The interaction of the two factors was not significant $[F(1,52)=3.68$, $\mathrm{p}>.05]$. A simple effects test revealed a PCE based on the comparison between Groups SL and LL $[F(1,52)=15.97, p<.01]$. The same test showed, however, that the downshifted subjects (Group LS) did not differ significantly from their controls (Group SS) $[F(1,52)=1.64, p>.05]$.

In addition, a two-way analysis of variance with repeated measures was carried out on mean total speed over the last six blocks of Phase 2, revealing significant main effects $[\mathrm{Fs}(1,52)=18.61$ and 21.08 for Phase 1 and Phase 2 conditions, respectively, both ps $<.01]$. The interaction effect was not significant $[\mathrm{F}(1,52)=3.66$, $p>.05]$. The blocks effect, as well as all possible interaction effects, was not significant (all Fs $<1$ ), indicating that the performance of groups had stabilized by the end of Phase 2. Individual comparisons again yielded a significant PCE $[F(1,52)=19.29, p<.01]$, but no NCE was obtained $[F(1,52)=2.9, p>.05]$.

Separate two-way analysis of variance tests of mean start, run, and goal speeds were performed over all blocks. For the start section, the main effect for Phase 1 condition was nonsignificant $(F<1)$. However, the main effect for Phase 2 and the interaction of the two factors were significant $[\mathrm{Fs}(1,52)=8.04$ and 7.95 , respectively, both ps<.01]. A test of simple effects showed a significant PCE $[F(1,52)=6.49, p<.025]$, but a nonsignificant $\operatorname{NCE}[F(1,52)=2.07, \mathrm{p}>.05]$. The run section yielded significant main effects for both Phase 1 and Phase 2 factors $[\operatorname{Fs}(1,52)=11.45$ and 10.79 , respectively, both ps $<.01]$, but a nonsignificant interaction effect $[F(1,52)=2.07, p>.05]$. The results of a simple effects test again showed a significant PCE $[F(1,52)=11.64, p<.01]$ and a nonsignificant NCE $[F(1,52)=1.89, p>.05]$. The goal section yielded significant main effects $[\mathrm{Fs}(1,52)=14.50$ and 10.14 for Phase 1 and Phase 2 conditions, respectively, both $\mathrm{ps}<.01]$ and a significant interaction effect
$[F(1,52)=4.05, p<.05]$. The results of a test of simple effects also yielded a significant PCE $[F(1,52)=16.94$, $\mathrm{p}<.01]$, but a nonsignificant $\mathrm{NCE}[\mathrm{F}(1,52)=1.61$, $\mathrm{p}>$.05].

Similar analyses of variance were performed on mean start, run, and goal speeds over Blocks 4-9, yielding results that, with one exception, were identical to those based on the analysis of the entire blocks. Specifically, the analysis of the start and goal speeds yielded only a PCE as before $[F s(1,52)=8.12$ and 15.54 , respectively, both ps $<.01]$, but the results of the analysis of the run speeds yielded significant positive and negative contrast effects $\left[F_{s}(1,52)=15.54\right.$ and 4.29 , ps $<.01$ and .05 , respectively].

As can be seen in Figure 1, the upshifted group ran faster than its control over Blocks 5-9 in Phase 3. Since after the second shift there was no longer a complete two-factor design, a one-way analysis of variance test with four independent groups was performed on the mean total speeds over Blocks 5-9. The main effect, however, was not significant $[\mathrm{F}(3,52)=1.81, \mathrm{p}>.05]$. A similar analysis of the start speed did reveal a significant main effect $[F(3,52)=3.39, p<.05]$. A significant PCE was obtained with a test of simple effects comparing Groups LSL and LLL $[F(1,52)=6.53, p<.025]$. A test of simple effects for NCE yielded nonsignificant results $(F<1)$. Similar analysis of variance tests of the run and goal speeds produced nonsignificant main effects (both Fs $<1$ ). A closer inspection of the data, however, also revealed that the downshifted group did run slower than its control group in the run section of the runway on Trial 2 over Blocks 4-9. Comparison of Groups SLS and SSS yielded a significant NCE $[F(1,52)=6.31, p<.025]$.

\section{DISCUSSION}

The major finding of the present study is the occurrence of both a positive and a negative contrast effect in the first shift, 
thus supporting the first hypothesis that predicted such a finding. Apparently, this is the first demonstration of contrast effects based on shifts in magnitude of water reward under conditions of superimposed delay. The occurrence of PCE in the present study extends the generality of previous findings based on shifts in the magnitude of food reward under similar delayed conditions (Mellgren, 1972; Shanab et al., 1969). Apparently, in both food and water studies, superimposed delay can be used to effectively control for ceiling effects, thus enhancing the emergence of positive contrast.

Unlike the PCE, which appeared in all sections of the runway on the first block and continued until the end of the first shift phase, the NCE appeared only in the run section starting with the fourth block. Since the subjects' running speed was considerably depressed in the start and goal sections (the overall mean speed for the start and goal sections were $.44 \mathrm{msec}$ and $.38 \mathrm{msec}$, respectively) relative to the run section (the mean run speed was $.70 \mathrm{msec}$ ), the absence of the NCE in the initial and terminal sections of the runway probably resulted from a floor effect produced by the delay interval. On the assumption that delay evokes frustration (cf. Shanab, 1971; Shanab \& Cavallaro, 1973), the cues near the goal area would be expected to evoke avoidance responses, because of the close temporal and spatial contiguity between these cues and the experience with delay.

For the same reasons, the cues in the startbox should also evoke competing responses, particularly since the massing of trials would bring these cues in closer temporal contiguity with delay than the run section cues. Thus, the run section would be relatively unhampered by the aversiveness of delay, which would account for the remarkably fast running speed obtained in that section. The same general reasoning would explain the absence of a PCE during the second shift in all but the start section. Similarly, no NCE was obtained in Phase 3 except on the second, or massed, trial of the run section. The results of the second shift indicate that both contrast effects were weaker than those obtained in the first shift, which is contrary to predictions as well as to other findings based on repeated shifts in sucrose (Shanab et al., 1976) or food reward (Benefield, Oscos, \& Ehrenfreund, 1974). In view of the relative ease of obtaining contrast effects in the first shift, the present discrepancy is puzzling. However, as Capaldi (1967) proposed earlier, no contrast effects should be obtained following repeated or transfer shifts, especially when downshifts are involved. The dearth of studies investigating shifts in water reward makes it difficult to provide an adequate theoretical account of the present findings.

\section{REFERENCES}

Barnes, W., \& Tombaugh, T. N. Another failure to obtain negative incentive contrast following reductions in sucrose reward. Psychological Reports, 1973, 33, 801-802.

Benefield, R., Oscos, A., \& Ehrenfreund, D. Role of frustration in successive positive contrast. Journal of Comparative and Physiological Psychology, 1974, 86, 648-651.

BowER, G. H. A contrast effect in differential conditioning. Journal of Experimental Psychology, 1961, 62, 196-199.
Capaldi, E. J. A sequential hypothesis of instrumental learning. In K. W. Spence \& J. T. Spence (Eds.), The psychology of learning and motivation (Vol. 1). New York: Academic Press, 1967. Pp. 67-156.

Capaldi, E. J. Successive negative contrast effect: Intertrial interval, type of shift, and four sources of generalization decrement. Journal of Experimental Psychology, 1972, 96, 433-438.

Cox. W. M. A review of recent incentive contrast studies involving discrete-trial procedures. The Psychological Record, 1975, 25, 373-393.

CResPI, L. P. Quantitative variations of incentive and performance in the white rat. American Journal of Psychology, 1942, 55, 467-517.

Dunham, P. J. Contrasted conditions of reinforcement: A selective critique. Psychological Bulletin, 1968, 69, 295-315.

Ferrell, H. J., \& Shanab, M. E. Contrast effects as a function of shifts in delay of water reward. Bulletin of the Psychonomic Society, 1975, 5, 417-420.

Flaherty, C. F., Riley, E. P., \& Spear, N. E. Effects of sucrose concentration and goal units on running behavior in the rat. Learning and Motivation, 1973, 4, 163-175.

Ison, J. R., \& Rosen, A. J. Extinction and reacquisition performance as a function of sucrose-solution rewards and number of acquisition trials. Psychological Reports, 1968, 22, 375-379.

Mellgren, R. L. Positive and negative contrast effects using delayed reinforcement. Learning and Motivation, 1972, 3, 185-193.

Rosen, A. J. Incentive shift performance as a function of magnitude and number of sucrose rewards. Journal of Comparative and Physiological Psychology, 1966, 62, 487-490.

SGro, J. A., \& Weinstock, S. Effects of delay on subsequent running under immediate reinforcement. Journal of Experimental Psychology, 1963, 66, 260-263.

Shanab, M. E. Positive transfer between nonreward and delay. Journal of Experimental Psychology, 1971, 91, 98-102.

Shanab, M. E., Birnbaum, D. W., \& Cavallaro, G. Positive contrast obtained following interpolation of nonreinforced or partially reinforced trials. Learning and Motivation, 1974, 5, 258-271.

Shanab, M. E., \& Cavallaro, G. Transfer between nonreward and delay of reward following minimal acquisition training. Animal Learning \& Behavior, 1973, 1, 179-182.

Shanab, M. E., Domino, J., \& Melrose, S. The effects of shifts in delay of liquid sucrose reward in thirsty rats. Bulletin of the Psychonomic Society, 1977, 10, 287-290.

Shanab, M. E., France, J., \& Young, T. Positive and negative contrast effects obtained following shifts in liquid sucrose reward in thirsty rats. Animal Learning \& Behavior, 1976, 4, 9-12.

Shanab, M. E., Sanders, R., \& Premack, D. Positive contrast in the runway obtained with delay of reward. Science, 1969, 164, 724-725.

(Received for publication June 6, 1978.) 